\title{
Neuroestrogens Rapidly Regulate Sexual Motivation But Not Performance
}

\author{
Aurore L. Seredynski, ${ }^{1}$ Jacques Balthazart, ${ }^{1}$ Virginie J. Christophe, ${ }^{1}$ Gregory F. Ball, ${ }^{2}$ and Charlotte A. Cornil ${ }^{1}$ \\ ${ }^{1}$ Groupe Interdisciplinaire de Génoprotéomique Appliquée (GIGA) Neurosciences, Research Group in Behavioral Neuroendocrinology, University of Liège, 4000 \\ Liège, Belgium, and ²Department of Psychological and Brain Sciences, Johns Hopkins University, Krieger School of Arts and Sciences, Baltimore, Maryland 21218
}

\begin{abstract}
Estrogens exert pleiotropic effects on reproductive traits, which include differentiation and activation of reproductive behaviors and the control of the secretion of gonadotropins. Estrogens also profoundly affect non-reproductive traits, such as cognition and neuroprotection. These effects are usually attributed to nuclear receptor binding and subsequent regulation of target gene transcription. Estrogens also affect neuronal activity and cell-signaling pathways via faster, membrane-initiated events. How these two types of actions that operate in distinct timescales interact in the control of complex behavioral responses is poorly understood. Here, we show that the central administration of estradiol rapidly increases the expression of sexual motivation, as assessed by several measures of sexual motivation produced in response to the visual presentation of a female but not sexual performance in male Japanese quail. This effect is mimicked by membrane-impermeable analogs of estradiol, indicating that it is initiated at the cell membrane. Conversely, blocking the action of estrogens or their synthesis by a single intracerebroventricular injection of estrogen receptor antagonists or aromatase inhibitors, respectively, decreases sexual motivation within minutes without affecting performance. The same steroid has thus evolved complementary mechanisms to regulate different behavioral components (motivation vs performance) in distinct temporal domains (long- vs short-term) so that diverse reproductive activities can be properly coordinated to improve reproductive fitness. Given the pleiotropic effects exerted by estrogens, other responses controlled by these steroids might also depend on a slow genomic regulation of neuronal plasticity underlying behavioral activation and an acute control of motivation to engage in behavior.
\end{abstract}

\section{Introduction}

Estrogens affect multiple reproductive endpoints, such as the development of secondary sexual characteristics, gonadotropin secretion, or activation of reproductive behaviors, but also non-reproductive traits, such as cognition. These effects typically are associated with long-term changes in physiological state (e.g., a non-reproductive vs a reproductive state characteristic of seasonally breeding species). They usually require a relatively long (i.e., hours to days) exposure to gonadally derived estrogens and are mediated by nuclear actions of estrogens that modulate transcription through binding to their cognate nuclear receptors (Tsai and O'Malley, 1994; Etgen and Pfaff, 2009). This original view of estrogen action has recently undergone a radical transformation.

Received May 27, 2012; revised Oct. 31, 2012; accepted Nov. 4, 2012.

Author contributions: A.L.S., J.B., G.F.B., and C.A.C. designed research; A.L.S. and V.J.C. performed research; J.B. and C.A.C. contributed unpublished reagents/analytic tools; A.L.S., V.J.C., and C.A.C. analyzed data; A.L.S., J.B., G.F.B., and C.A.C. wrote the paper.

This research was supported by National Institute of Mental Health Grant MH50388 (J.B. and G.F.B.), the Belgian Basic Research Collective Grant 2.4537.09, and the University of Liège Special Funds 2009 (J.B.). C.A.C. is National Fund for Scientific Research research associate. We thank Catherine de Bournonville for her help with the statistical analysis. We are grateful to Dr. Margaret M. McCarthy and Dr. J. Martin Wild for their comments on previous versions of this manuscript.

The authors declare no competing financial interests.

Correspondence should be addressed to Charlotte A. Cornil, University of Liège, Groupe Interdisciplinaire de Génoprotéomique Appliquée (GIGA) Neurosciences, Research Group in Behavioral Neuroendocrinology, 1 avenue de l'Hopital (B36), 4000 Liège, Belgium. E-mail: charlotte.cornil@ulg.ac.be.

DOI:10.1523/JNEUROSCI.2557-12.2013

Copyright $\odot 2013$ the authors $\quad 0270-6474 / 13 / 330164-11 \$ 15.00 / 0$
Although it was known that estrogen synthesis by testosterone (T) aromatization occurs in various tissues, including the brain (Naftolin et al., 1975; Santen et al., 2009), the recent demonstration that aromatase activity and brain estrogen concentrations are regulated within minutes in vitro and in vivo by neuronal activity (Balthazart and Ball, 2006; Remage-Healey et al., 2008, 2011; Charlier et al., 2011; Cornil et al., 2012) suggests the existence of rapidly changing local estrogen concentrations that could affect brain physiology in a shorter timeframe. In other words, in addition to seasonal changes in physiology resulting from variations in circulating concentrations of estrogens or its precursor $\mathrm{T}$, local estrogen synthesis appears to be acutely regulated in the brain and could in turn affect neural activity in the short term. This is a potentially exciting prospect because, during the reproductive season, many behavioral or physiological events are regulated on a much shorter timescale. For example, sexual behavior is not displayed continuously but rather is modulated on a very short timescale. It was always assumed that such shortterm changes in behavior were regulated by neurotransmitter systems. Could steroids be responsible for both long-term and short-term variations in behavioral production?

In vitro studies established that estrogens rapidly activate (within seconds to minutes) numerous intracellular signaling pathways, which in turn regulate neuronal activity (Woolley, 2007). These cellular effects are often transient and initiated by either nuclear receptors associated with the cell membrane (Micevych and Dominguez, 2009) or novel membrane estrogen receptors (Qiu et al., 2003; Revankar et al., 2005). Although some 
studies have identified rapid effects of estrogens on behavioral responses (Kow and Pfaff, 2004; Tremere et al., 2009; RemageHealey et al., 2010; Tremere and Pinaud, 2011), including effects on male copulatory behavior (for details, see Cornil et al., 2012), such evidence remains scarce. Moreover, evidence concerning male sexual behavior is often poorly reproducible (Cross and Roselli, 1999; Cornil et al., 2006a,b). In particular, whether brainderived estrogens also affect male sexual behavior by nongenomic mechanisms and why these two types of signaling would have evolved to mediate estrogen action on the same response is not known. The present study addresses the first of these questions in male Japanese quail, a well-established model for the study of the role of brain-derived estrogens (neuroestrogens) in male sexual behavior (Ball and Balthazart, 2010). Our findings indicate that estrogens have evolved complementary mechanisms to regulate different behavioral components (motivation vs performance) in distinct temporal domains.

\section{Materials and Methods Animals}

Forty-three male Japanese quail (Coturnix japonica) belonging to three independent groups served as subjects in these experiments. Birds were obtained from the breeding colony established in our laboratory (groups 1 and 2) or a local breeder (group 3). In male quail, reproduction is tightly controlled by variations in photoperiod that regulate both gonadal growth and gonadal regression (Robinson and Follett, 1982). To fully stimulate their hypothalamic-pituitary-gonadal axis, birds were exposed throughout their life to a photoperiod simulating long summer days ( $16 \mathrm{~h}$ light $/ 8 \mathrm{~h}$ dark), although these animals were castrated (CX) and chronically supplemented with exogenous $\mathrm{T}$ (see below). They had food and water available ad libitum. All experimental procedures were in agreement with the Belgian laws on the "Protection and Welfare of Animals" and on the "Protection of Experimental Animals" and were approved by the Ethics Committee for the Use of Animals at the University of Liège.

All birds were castrated as described previously (Balthazart et al., 1998) at the age of 3 weeks when the testes are still small and quiescent before puberty. This manipulation has no effect on the sexual differentiation of the individuals because the window framing the critical period for sexual differentiation has been long closed by this time (Balthazart et al., 2009a). The birds then remained housed in groups until the age of 6 weeks, when they were moved to individual cages. At the age of 8 weeks, all birds were implanted in the third ventricle with a chronic 22 gauge injection guide cannula containing a 28 gauge dummy insert (C313G and C313I; Plastics One). Coordinates of the cannula tip were $1.80 \mathrm{~mm}$ anterior, $2.80 \mathrm{~mm}$ dorsal, and $0.00 \mathrm{~mm}$ lateral to the zero reference point (center of the interaural axis) using an angular approach $\left(10^{\circ}\right.$ away from the vertical) to avoid the sagittal sinus present in medial position at the surface of the brain (see detail of methods in the study by Cornil et al., 2005a). The location of the cannula in the ventricle was confirmed at implantation and before any injection by the observation of a drop of CSF flowing out of the tip of the cannula when the dummy insert was removed (Cornil et al., 2005a; Kleitz-Nelson et al., 2010). All birds were then implanted subcutaneously in the neck region with one 20 -mm-long SILASTIC tube (1.57 mm inner diameter, $2.41 \mathrm{~mm}$ outer diameter, Silclear Tubing; Degania Silicone) filled with crystalline $\mathrm{T}$ (Sigma) to mimic the increase in gonadal secretion occurring approximately at this age and fully activate male-typical behaviors (Balthazart et al., 1990a).

Intracerebroventricular injections and behavioral tests were started 2 weeks after the beginning of $\mathrm{T}$ treatment. Intracerebroventricular injections in the third ventricle were performed with a $5 \mu$ l Hamilton syringe connected to a microinfusion pump (model KDS-220; KD Scientific). The dummy cannula was replaced by a 28 gauge internal cannula (C313C; Plastics One) attached to the syringe by a cannula connector. The liquid ( 1 or $2 \mu$ l depending on the dose and drug) was infused at the rate of $0.5 \mu \mathrm{l} / \mathrm{min}$, resulting in injection durations of 2 and $4 \mathrm{~min}$ for the injection of 1 or $2 \mu \mathrm{l}$, respectively. The internal cannula was left in place for $1 \mathrm{~min}$ before being removed to allow diffusion of the solution into the CSF and avoid its leakage outside of the brain. The internal cannula was then slowly lifted and replaced by the dummy cannula.

The size of the cloacal gland, an androgen-dependent structure, was periodically measured with calipers to confirm the effectiveness of chronic $\mathrm{T}$ treatment of the birds because it was demonstrated previously that this size is a highly accurate and sensitive measure of peripheral $\mathrm{T}$ concentrations (Sachs, 1967) and that variation in the size of this gland integrates changes in circulating T over a long period of time (Delville et al., 1984; Balthazart et al., 1990a). Animals were also regularly weighed to confirm the absence of adverse effect of treatments on their general health condition.

\section{General procedures}

Previous studies have shown that a single systemic administration of estradiol $\left(\mathrm{E}_{2}\right)$ or of an aromatase inhibitor, mimicking an increased or decreased bioavailability of estrogens, respectively, acutely facilitates or reduces male sexual behavior in birds as well as rodents (Cross and Roselli, 1999; Cornil et al., 2006a,b; Taziaux et al., 2007). However, these studies did not provide any information regarding the origin of the estrogens that modulate behavior (brain vs periphery) and suffered from high variability and/or poor reproducibility. These issues might partially be circumvented by administering treatments directly in the brain rather than in the periphery. In addition, the detection of these acute effects of estrogens on behavior may critically depend on the endocrine status of the experimental animals that may constrain the potential interactions between genomic and nongenomic actions of estrogens (see Discussion). In the present study, we thus decided to use two separate but complementary approaches during 17 separate experiments performed on three independent groups of birds to assess the acute effects of estrogens on male sexual behavior. Both approaches involved the administration of various steroidal and nonsteroidal drugs directly into the brain via a cannula implanted in the third ventricle.

The first approach was based on our previous observation that the effects of acute estrogens cannot be detected in castrates or males exposed to physiological concentrations of estrogens (C.A.C. and J.B., unpublished observations) and were not observed consistently in males exposed to low concentrations of $\mathrm{T}$ [and its androgenic and estrogenic metabolites; (Cornil et al., 2006a)]. Therefore, we decided in this first approach (experiments $1-3$ on birds from group 1) to mimic an increase in $E_{2}$ bioavailability by acutely injecting $\mathrm{E}_{2}$ to $\mathrm{CX}$ males chronically treated with $\mathrm{T}$ but also chronically deprived of estrogens through twice daily injections of the potent aromatase inhibitor Vorozole (6-[(4-chlorophenyl)(1H-1,2,4-triazol-1yl)methyl]-1-methyl-1 $H$-benzotriazole) (VOR). These males are thus exposed to the full range of purely androgenic effects but are not subjected to any estrogenic action (genomic or nongenomic). It was hypothesized that, if nongenomic actions of estrogens are involved in the control of male sexual behavior, $E_{2}$ injections should acutely restore parts of this behavior unless some degree of genomic priming by estrogens (e.g., $\mathrm{E}_{2}$-induced induction of transcription of a membrane estrogen receptor) is required for nongenomic actions to take place. Although one could expect that the long-term blockade of aromatase would result in an elevation of $\mathrm{T}$ concentrations, a very small proportion of aromatizable androgens only (far less than 1\%) is actually converted locally into estrogens in avian and mammalian species (Roselli et al., 1985; Hutchison et al., 1986; Cornil et al., 2011). As a consequence, the effects of chronic VOR treatment are unlikely the result from an elevation in androgens, but they rather reflect the lack of a genomic action of estrogens.

In contrast, the second approach (experiments 4-17 on birds from groups 2 and 3) was designed to mimic an acute reduction of estrogen bioavailability through the acute blockade of estrogen synthesis (by aromatase inhibitors) or action (by estrogen receptor antagonists) in CX males chronically treated with exogenous $\mathrm{T}$ such that they displayed the full suite of male-typical behaviors. If an effect of acute blockade of aromatization was detected, it was then planned to assess the reversibility of this effect by injecting various estrogenic compounds to determine the specificity of the response.

These two approaches are complementary in that (1) they analyze the mechanisms leading to the activation as well as the suppression of the same behavioral response and (2) they should provide insights into 
the interplay between genomic and nongenomic actions of estrogens in the control of the same behavioral output.

Three groups of animals were used for the three different series of experiments. Regardless of the group considered, all animals were repeatedly tested with all drugs in a withinsubject design. Practically, the animals were first tested (see specific experiments design) to ensure that they were in the appropriate conditions (preliminary phase). When ready to enter the acute phase of the experiment (see details of specific experiments), birds were assigned to different subgroups that did not differ with respect to their average behavioral frequencies displayed during the preliminary phase nor to morphological features (cloacal gland size and body mass). These subgroups were repeatedly tested on different days with different drugs (one drug vs its vehicle or two drugs vs their vehicle; for details of design, see Fig. 1), but each subgroup received these drugs in a different order. This procedure allowed us to control for any long-lasting effect of the drugs attributable to the activation of genomic actions or the slow clearance of the drug in the birds. In addition, to ensure that the treatments did not exert long-lasting effects on the behavior, all birds of groups 2 and 3 were pretested after a vehicle injection before each series of experimental treatments (pretest), as well as after them (posttest). The vehicle injection was always given following the same timing as the timing of the experimental drug(s) tested. The comparison of pretest and posttest allowed us to evaluate the stability of the behavioral responses despite multiple experimental treatments. The combination of the pretest, the multiple tests comparing one or two compounds with the vehicle (control), and the posttest constitutes an experiment (Fig. 1). The interval between individual tests varied depending on the experimental design in which the groups were tested. Each group of birds participated in several experiments testing the effects of different drugs, administered at different doses and timings, on different behavioral measures (see detail in the following sections).

These experiments investigated rapid controls by estrogens of both the appetitive (variable behaviors that serve to bring individuals in contact with their sexual partner, often used as a measure of sexual motivation, e.g., courtship) and consummatory (highly stereotyped behaviors allowing sperm transfer and leading to the reduction of sexual motivation, i.e., sexual satiety) aspects of male sexual behavior. Both components are activated by prolonged genomic effects of estrogens (Balthazart et al., 1998, 2009b; Taziaux et al., 2004), but whether they are also regulated by estrogens acting in a rapid mode was unclear when we started these experiments.

\section{Behavioral tests}

\section{Appetitive sexual behavior}

Two measures were used to assess appetitive sexual behavior (ASB): the frequency of the rhythmic cloacal sphincter movements (RCSM) and the learned social proximity response (LSPR).

The frequency of RCSM was quantified by placing the experimental male in one side of a glass aquarium $(40 \times 20 \times 25 \mathrm{~cm})$ located on a raised platform with a mirror placed underneath at a $45^{\circ}$ angle that provided an unobstructed view of the cloacal area (Balthazart et al., 1998; Seiwert and Adkins-Regan, 1998). During the first phase of the test, a stimulus female was placed on the other side of the aquarium separated from the male by a glass partition and a vertically sliding opaque panel that prevented the animals from seeing each other. In the second phase of
Tests
(Exp. treatments)

Day 1 Day 2

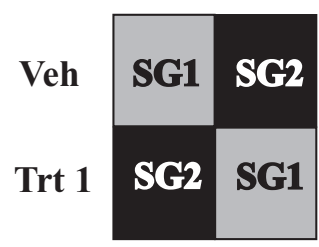

Tests

(Exp. treatments)

Day 1 Day 2 Day 3

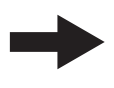

SG1

SG2

Post

(Ctrl)
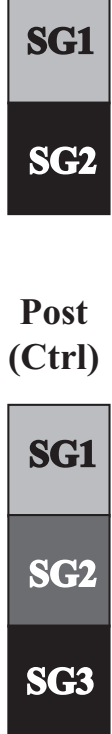

Figure 1. Experimental design used when comparing the effect of one $(\boldsymbol{A})$ or two $(\boldsymbol{B})$ experimental (Exp.) treatment(s) to their

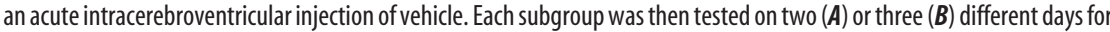
half received the vehicle first and experimental treatment second. In the posttest, all birds were tested again after an injection of vehicle. In these experiments, all tests were given either $2 \mathrm{~d}$ (group 1) or $3 \mathrm{~d}$ apart (groups 2 and 3 ).

this test, the opaque panel was raised, allowing visual access to the female although the male could still not physically interact with her. The number of RCSM was recorded for 2.5 min before (phase 1) and during (phase 2) the view of the female. Several lines of evidence indicate that this measure is indicative of the male's motivation to approach its mate. Indeed, previous studies showed that the RCSM frequency (1) rapidly increases in sexually active males provided with the view of a female but not when provided with a view of a male (Seiwert and Adkins-Regan, 1998; Thompson et al., 1998), (2) is readily displayed by naive males without previous sexual learning but can also be conditioned and elicited by an arbitrary stimulus previously associated with the presentation of a sexual stimulus, such as visual access to a female (Cornil et al., 2004; Holloway et al., 2005; Cornil and Ball, 2010), (3) decreases after castration but is restored after supplementation with exogenous T (Balthazart et al., 1998), (4) is reduced after copulation (M. Schmit, C. de Bournonville, and C. A. Cornil, unpublished observations), and (5) is inhibited by lesions of the preoptic area, a brain region known to control male sexual behavior (Balthazart et al., 1998). Together, these observations strongly suggest that these cloacal contractions constitute a preparatory or appetitive response in anticipation of copulation that reflects the propensity of the male to engage in copulation (i.e., a measure of his underlying sexual motivation).

The LSPR is a form of associative learning in which males learn to stand in front of a narrow window in which they had previously been able to see a sexually receptive female (Domjan and Hall, 1986). Animals used here were allowed to acquire and express this response in conditions similar to those described previously (Balthazart et al., 1998). Briefly, the conditioning and tests took place in four two-compartment chambers. Each chamber consisted of a large compartment $(90 \times 90 \times 50 \mathrm{~cm})$ where the male is placed at the beginning of each test and a smaller adjacent compartment $(20 \times 60 \times 24 \mathrm{~cm})$ housing the stimulus female. 
The two compartments are separated by a vertically sliding door that can be remotely controlled by strings and pulleys. A narrow vertical slit $(1 \mathrm{~cm}$ wide $\times 15 \mathrm{~cm}$ high) is located in the middle of this door and serves as a "window" that provides the male with a limited visual access to the female. A square area $(30 \times 30 \mathrm{~cm})$ located on the floor of the main compartment in front of this door represents the test zone for the bird's position. The male present in the main compartment can only see the female located in the side compartment if he stands in front of the window in the test area. A male learns to stand continuously in front of the window providing visual access to the female after he has had a chance to copulate with her in the experimental setup. Only one copulation is necessary to establish this response.

Each behavioral test lasted a total of $10 \mathrm{~min}$. The male was first placed in the main compartment, and the stimulus female was introduced in the adjacent smaller compartment. The amount of time that the male spent in the square test area in front of the window (Square) as well as the time that he actually spent looking through the window (Look) was recorded for $5 \mathrm{~min}$. Looking behavior was defined as a stereotyped positioning of the male's head such that he could focus on the female through the narrow slit in the door. These data provided a measure of the appetitive behavior. Then, the door separating the two compartments was raised, allowing the two birds to physically interact for another $5 \mathrm{~min}$, during which the frequency and latency of first occurrence of copulatory behaviors were directly recorded (see below). The animals were then moved back to their home cage until the next day.

In the present experiment, eight acquisition tests were performed on 8 successive days that allowed all males to acquire a stable conditioned response. Birds were then tested in extinction (female not released during the second period of $5 \mathrm{~min}$ ) in two additional tests to ensure that, as previously described, the response remains stable even in the absence of reinforcement (Domjan and Hall, 1986; Balthazart et al., 1995). The effect of different endocrine treatments was then tested as detailed in the specific section devoted to group 3. Importantly, the acquisition of this social proximity response occurs (1) only in gonadally intact males or castrates chronically treated with T (Balthazart et al., 1995, 1998), (2) only if males have been able to copulate in this experimental setup (Balthazart et al., 1995), and (3) in response to female but not male stimuli (Domjan et al., 1992). Additionally, (4) the learned response is markedly reduced after lesions of the preoptic area (Balthazart et al., 1998). Together, these observations indicate that this learned response constitutes another good measure of ASB and reflects the propensity of the male to engage in copulation (i.e., a measure of his underlying sexual motivation).

\section{Consummatory sexual behavior}

Consummatory sexual behavior (CSB) was assessed after presentation of a sexually mature female with which the male could freely interact during $5 \mathrm{~min}$ in three different test arenas: a small $(60 \times 40 \times 50 \mathrm{~cm}$; used during all preliminary phases and for experimental tests in all groups) or large arena $(90 \times 90 \times 50 \mathrm{~cm}$; used for experimental tests in groups 2 and 3 only) or the small aquarium used to quantify RCSM after removal of the glass partition between the two compartments immediately after the RCSM test (during the experimental phase in group 1). The frequency of behavioral patterns that are part of the copulatory sequence, including neck grabs, mount attempts, mounts, and cloacal contact movements (CCM) (for a detailed description of these behaviors, see Adkins and Adler, 1972; Hutchison, 1978) was recorded by an observer blind to the treatments. Data relative to these four behavioral measures have been analyzed and yielded the same statistical results and conclusions. As a consequence, to avoid redundancy, only CCM results are shown here.

\section{Specific experimental procedures}

Effects of acute estrogen treatment in males chronically deprived of estrogens (first group of birds)

Preliminary phase. Two weeks after T implantation, 16 males were pretested in small test chambers until they all displayed the full range of copulatory behaviors. They were then injected twice daily in the pectoral muscles with the potent aromatase inhibitor VOR ( $1 \mathrm{mg} / \mathrm{kg} ; n=12$; Balthazart et al., 1990b) or its vehicle propylene glycol (PG)/saline (4:1;
Table 1. Details of experiments 1-3 conducted on the first group of males

\begin{tabular}{lllllcl}
\hline Experiment & Test & Arena & $n$ & Drugs & Doses $(\mu \mathrm{g})$ & Latency $(\mathrm{min})$ \\
\hline 1 & $\mathrm{RCSM} / \mathrm{CCM}$ & Aquarium & 12 & $\mathrm{E}_{2}$ & 50 & 15 \\
2 & $\mathrm{RCSM} / \mathrm{CCM}$ & Aquarium & 12 & $\mathrm{E}_{2}$ & 100 & 15 \\
3 & $\mathrm{RCSM} / \mathrm{CCM}$ & Aquarium & 11 & $\mathrm{E}_{2}-\mathrm{BSA}$ & $50^{a}$ & 15 \\
\hline
\end{tabular}

The experiments numbers (1-3) correspond to the order in which they were performed.

${ }^{a} E_{2}-B S A$ was administered at a dose equivalent to $50 \mu \mathrm{g}$ of free estradiol following information provided by the manufacturer.

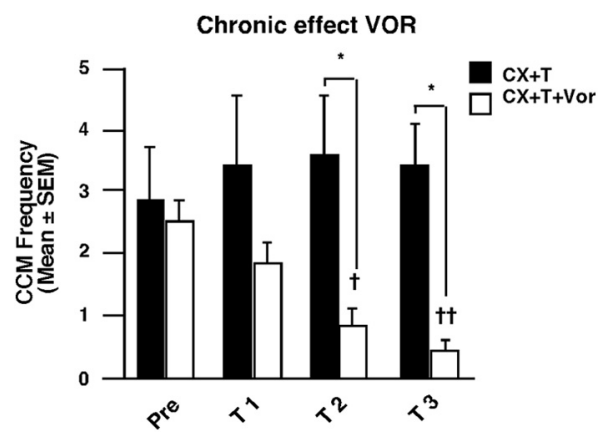

Figure 2. Chronic treatment with the aromatase inhibitorVOR almost completely eliminates CSB (group 1, preliminary phase). After the last pretest (Pre), CX males chronically treated with T were injected twice daily with VOR (1 mg/kg, i.m.; white bars, $C X+T+V O R, n=12)$ or its vehicle (PG; controls, black bars, $C X+T, n=4$ ). Birds were then repeatedly tested every third day for the expression of CSB. CCM frequencies gradually decreased to almost zero within $9 \mathrm{~d}$. Data were analyzed by two-way ANOVA with treatment as independent factor $\left(F_{(3,51)}=1230\right.$, $p=0.308)$ and successive tests as repeated factor $\left(F_{(1,17)}=17.532, p<0.001\right.$; interaction, $\left.F_{(3,51)}=3.758, p=0.016\right) .{ }^{*} p<0.05$ versus controls $(C X+T) ;{ }^{\dagger} p<0.05$ and ${ }^{{ }^{+}} p<0.01$ versus Pre same treatment, by Tukey's post hoc test.

$n=4)$ for the entire duration of the experiment ( $25 \mathrm{~d})$. To monitor the behavioral decline induced by this prolonged deprivation in estrogens (Taziaux et al., 2004), copulatory behavior was first evaluated before the first VOR injection. Starting on the second day after the beginning of the twice daily injection regimen, birds were then subjected to three additional tests for copulatory behavior until a significant behavioral decline was detected (Fig. 1). In a last test, all birds then received a vehicle intracerebroventricular injection and were tested in sequence for RCSM and copulatory behavior in the aquarium in which all experimental tests were performed subsequently. This pretest confirmed the behavioral inhibition affecting both RCSM and CCM observed previously. All behavioral tests took place $2 \mathrm{~h}$ after the morning injection and were given $3 \mathrm{~d}$ apart.

Experimental phase. VOR-treated birds were assigned to two experimental subgroups ( $n=6$ each) matched based on the mean behavioral frequencies displayed during the last preliminary test. These birds were involved in three experiments (Table 1) comparing the effect of the control injection of the vehicle (PG) with either $50 \mu \mathrm{g}$ of $\mathrm{E}_{2}$ (in $1 \mu \mathrm{l}$; experiment 1), $100 \mu \mathrm{g}$ of $\mathrm{E}_{2}$ (in $2 \mu \mathrm{l}$; experiment 2), or with its membrane-impermeant analog $\mathrm{E}_{2}$ coupled with bovine serum albumin ( $\mathrm{E}_{2}-\mathrm{BSA}$; for more discussion on this compound, see below, Drugs; 50 $\mu \mathrm{g}$ of $\mathrm{E}_{2}$ equivalent in $2 \mu \mathrm{l}$; experiment 3 ). Birds were tested every other day for $15 \mathrm{~min}$ after the intracerebroventricular injection of the experimental drug or the vehicle. As described in Figure $1 \mathrm{~A}$, treatments were administered in a different order to the two subgroups, such that all birds served as their own control but half of them were first treated with the vehicle whereas the other half received the experimental injection. Within the same experiment, animals were tested sequentially for ASB and CSB in the glass aquarium used for ASB quantification. As a consequence, the test lasted a total of $10 \mathrm{~min}: 2.5 \mathrm{~min}$ for RCSM in the absence of the female, $2.5 \mathrm{~min}$ for RCSM in the presence of the female, and $5 \mathrm{~min}$ for CCM. The control birds that were not treated with VOR (i.e., $\mathrm{CX}+\mathrm{T}$ birds) were tested in parallel after a control intracerebroventricular injection of PG. These animals served as a reference point for fully active birds (Figs. 2, 3, black histogram bars) but were not included in the statistical analysis of the acute experiments because they were not tested 
Table 2. Details of experiments 4-13 conducted on the second group of males

\begin{tabular}{|c|c|c|c|c|c|c|c|}
\hline Experiment & Order & Test & Arena & $n$ & Drugs & Doses $(\mu \mathrm{g})$ & Latency (min) \\
\hline 4 & 2 & RCSM & Aquarium & 15 & $\mathrm{ICl}$ and TMX & 100 & 15 \\
\hline 5 & 1 & RCSM & Aquarium & 15 & $\mathrm{ICl}$ and TMX & 100 & 30 \\
\hline 6 & 4 & $\mathrm{CCM}$ & Small & 13 & $\mathrm{ICl}$ and TMX & 100 & 15 \\
\hline 7 & 3 & $\mathrm{CCM}$ & Small & 15 & $\mathrm{ICl}$ and TMX & 100 & 30 \\
\hline 8 & 6 & RCSM & Aquarium & 12 & VOR and ATD & 50 & 30 \\
\hline 9 & 7 & $\mathrm{CCM}$ & Small & 12 & VOR and ATD & 50 & 30 \\
\hline 10 & 9 & RCSM & Aquarium & 12 & VOR and VOR $+E_{2}$ & $50 / 50$ & $30 / 15$ \\
\hline 11 & 10 & RCSM & Aquarium & 12 & VOR and VOR $+E_{2}-$ biotin & $50 / 50$ & $30 / 15$ \\
\hline 12 & 5 & $\mathrm{CCM}$ & Large & 14 & $\mathrm{ICl}$ and TMX & 100 & 30 \\
\hline 13 & 8 & $\mathrm{CCM}$ & Large & 12 & VOR and ATD & 50 & 30 \\
\hline
\end{tabular}

The experiment numbers follow the order in which the results are described, but the actual order in which the experiments were performed is provided in the second column. When $\mathrm{E}_{2}$ was administered along with VOR, the dose and timing of injection of both compounds are separated by the slash, with VOR being listed first.

Table 3. Details of experiments 14-17 conducted on the third group of males

\begin{tabular}{|c|c|c|c|c|c|c|c|}
\hline Experiment & Order & Test & Arena & $n$ & Drugs & Doses $(\mu \mathrm{g})$ & Latency (min) \\
\hline 14 & 1 & LSPR & Large & 16 & VOR versus VOR $+E_{2}$ & $50 / 50$ & $30 / 15$ \\
\hline 15 & 4 & RCSM & Aquarium & 9 & VOR versus VOR $+E_{2}$ & $50 / 50$ & $30 / 15$ \\
\hline 16 & 2 & $\mathrm{CCM}$ & Small & 9 & VOR versus VOR $+E_{2}$ & $50 / 50$ & $30 / 15$ \\
\hline 17 & 3 & $\mathrm{CCM}$ & Large & 9 & VOR versus VOR $+E_{2}$ & $50 / 50$ & $30 / 15$ \\
\hline
\end{tabular}

The experiment numbers follow the order in which the results are described, but the actual order in which the experiments were performed is provided in the second column. Because VOR and $\mathrm{E}_{2}$ were administered with different timings, the timing and doses of injections are both presented with VOR preceding $E_{2}$. LSPR, learned social proximity response.

with comparable experimental treatments. One bird lost its cannula between the $\mathrm{E}_{2}$ and $\mathrm{E}_{2}-\mathrm{BSA}$ tests and thus had to be excluded from experiment 3.

Effects of blockade of local estrogen action or synthesis in sexually active males (second group of birds)

Preliminary phase. Two weeks after T implantation, birds $(n=15)$ were offered several opportunities to copulate with a female to allow them to express the full repertoire of copulatory behavior and were tested once for RCSM to habituate them to the test arena.

Experimental phase. Based on the behavioral frequencies displayed during the preliminary phase, birds were assigned to one of three experimental subgroups ( $n=5$ each) matched based on the mean RCSM and $\mathrm{CCM}$ frequency produced during the preliminary phase. A total of 10 experiments were performed, each consisting of three repeated experimental tests (one vehicle vs two drugs) surrounded by two "baseline" tests (one pretest and one posttest) to assess the effects of the blockade of estrogen synthesis or action on the expression of ASB measured by RCSM and on CSB investigated in small or large arenas. The experiments compared the following drugs with the vehicle: two estrogen receptor antagonists [ICI 182,780 $(7 \alpha, 17 \beta$-[9-[(4,4,5,5,5-pentafluoropentyl)sulfinyl] nonyl] estra-1,3,5(10)triene-3,17-diol) (ICI), $100 \mu \mathrm{g}$; and tamoxifen (TMX), $100 \mu \mathrm{g}]$; two aromatase inhibitors [VOR, $50 \mu \mathrm{g}$; and 1,4,6-androstatrien-3,17-dione (ATD), 50 $\mu \mathrm{g}$ ]; and $\operatorname{VOR}(50 \mu \mathrm{g})$ with or without $\mathrm{E}_{2}(50 \mu \mathrm{g})$ or $\mathrm{E}_{2}$-biotin $\left(50 \mu \mathrm{g}\right.$ of $\mathrm{E}_{2}$ equivalent; a membrane-impermeant $\mathrm{E}_{2}$ analog; for more discussion on this compound, see below, Drugs). The effect of these drugs was tested after latencies of 15 or $30 \mathrm{~min}$ depending on the experiment. The details of these experiments and the order in which they were actually conducted are represented in Table 2. As illustrated in Figure 1B, each experiment started with a pretest during which all birds were tested after a control intracerebroventricular injection of PG. Then, the three subgroups were submitted to three independent tests assessing the effect of three treatments administered in different orders on ASB or CSB measured 15 or $30 \mathrm{~min}$ after injection. All birds were thus used as their own control, with the different subgroups receiving the same exact treatments but in different orders to avoid any possible effects in final results of long-term consequences of the acute treatments. Each series of three repeated tests was followed by a posttest after another control intracerebroventricular injection. All tests were conducted $3 \mathrm{~d}$ apart throughout the entire experiment. All compounds tested were diluted in $1 \mu \mathrm{l}$ of PG with the exception of the highest dose of $\mathrm{E}_{2}$ that was diluted in $2 \mu \mathrm{l}$ and administered intracerebroventricularly. Note that three birds (one in each subgroup) lost their cannula during the study and had thus to be excluded from the experiments, resulting in a decrease in degrees of freedom in the ANOVAs.

Effect of changes in brain-derived estrogens on the learned social proximity response in sexually active males (third group of birds) Preliminary phase. Two weeks after T implantation, birds $(n=18)$ were offered several opportunities to copulate with a female to acquire the full repertoire of copulatory behavior and tested once for RCSM to habituate to the test arena. As described above (see Behavioral tests), they received eight acquisition tests given on 8 consecutive days until they had developed a stable LSPR.

Experimental phase. The effects of the experimental treatments (VOR vs $\mathrm{VOR}+\mathrm{E} 2$ vs vehicle) were tested during the extinction phase of the learned social proximity response (that is when the female is no longer released from her cage in the second step of this test) to prevent any feedback from the experimentally induced decrease in copulatory behavior on the learned response (experiment 14) (Table 3). On the day after the last acquisition test, all birds received a first test in extinction. Two days later, they all received a vehicle intracerebroventricular injection 30 min before a second test, which constituted the reference test for the basal response (pretest). Birds were then assigned to one of three experimental subgroups ( $n=6$ each) matched based on the time spent in the square and time spent looking at the female in the second extinction test of the LSPR test. Then, three subgroups were repeatedly tested with the three experimental treatments administered intracerebroventricularly, each test given $3 \mathrm{~d}$ apart. Three days after the last experimental test, all subgroups were tested again after a vehicle intracerebroventricular injection serving as the posttest. A total of six tests were thus performed during the extinction phase; the experimental phase was conducted on the last five (one pretest, three experimental tests, and one posttest). Two birds in one subgroup lost their cannula during this experiment and were thus removed from the statistical analysis.

To replicate some of the data obtained with group 2, nine animals were selected randomly among this group of birds and were reassigned to three different subgroups $(n=3)$ based on their mean CCM and RCSM frequencies. They were then tested for the effects of VOR, VOR $+\mathrm{E}_{2}$, or their vehicle (PG) on copulatory behavior measured in the small (experiment 15) and large (experiment 16) test arena and on RCSM frequencies (experiment 17; Table 3). As was done previously, these experiments consisted of three experimental tests given $3 \mathrm{~d}$ apart surrounded by one pretest and one posttest given $3 \mathrm{~d}$ before and after the first and last experimental test, respectively (see Fig. $1 B$ and details of group 2). 


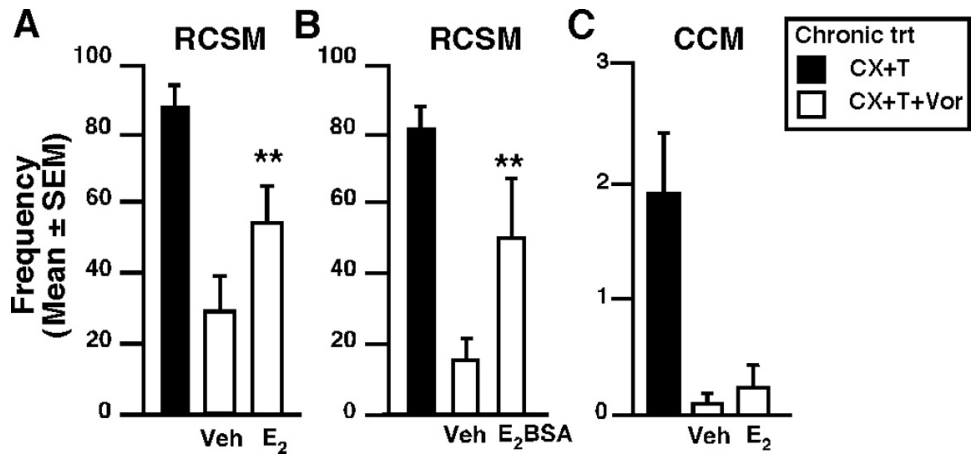

Figure 3. $E_{2}$ rapidly facilitates appetitive (ASB) but not consummatory sexual behavior (CSB) in males chronically deprived males of estrogens by its action at the membrane level (group 1, experimental phase). CX males were chronically treated with $T$ and the aromatase inhibitor VOR ( $C X+T+$ VOR, white bars) or with its vehicle $(C X+T$; black bars, $n=4)$. The estrogen-deprived males $(C X+T+V O R)$ were then acutely injected with $E_{2}\left(50 \mu \mathrm{g}, n=12, A, C\right.$, the membrane-impermeant analog $E_{2}-B S A$ (50 $\mu \mathrm{g}, n=11, \boldsymbol{B})$, or the vehicle (Veh) and tested 15 min later for $\operatorname{ASB}(\boldsymbol{A}, \boldsymbol{B})$ or $\mathrm{CSB}(\boldsymbol{C})$ assessed by the frequency of RCSM and of CCM, respectively. Data from $C X+T$ males (black bars) are shown as reference of fully stimulated behavior but were not integrated in the final analyses. ${ }^{* *} p<0.01$ versus vehicle by Fisher's LSD post hoc test after identification of a significant treatment effect (repeated-measure) by two-way ANOVA.

\section{Drugs}

VOR was graciously provided by Dr. R. DeCoster (Janssen Research Foundation, Beerse, Belgium). PG, $17 \beta-\mathrm{E}_{2}, \mathrm{E}_{2}-\mathrm{BSA}$ (membraneimpermeant analog of $\mathrm{E}_{2}$ ), ICI (Fulvestran), TMX, and $\mathrm{T}$ were obtained from Sigma. ATD and $\mathrm{E}_{2}$-biotin (another membraneimpermeant analog of $\mathrm{E}_{2}$ ) were obtained from Steraloids.

Two membrane-impermeant $\mathrm{E}_{2}$ analogs were used here. $\mathrm{E}_{2}-\mathrm{BSA}$ is most commonly used in the literature, but there have been doubts regarding its stability and the purity of the commercially available product (Stevis et al., 1999). $\mathrm{E}_{2}$-biotin was thus also used based on its recent use for a similar purpose (Dewing et al., 2007; Remage-Healey and Joshi, 2012) and the demonstration of a somewhat higher stability (Germain et al., 1993).

\section{Data analyses}

In each of the 17 separate experiments, results obtained in pretests and posttests were compared with each other with paired-samples $t$ tests. Data comparing the effects of experimental treatments in each of the 17 independent experiments were analyzed by two-way ANOVAs with treatments as the repeated factor and their order (two or three subgroups) as the independent factor to exclude the possibility of long-term effects of treatments that would interfere with the short-term effects under investigation. When significant, these ANOVAs were followed by post hoc Fisher's least significant difference (LSD) tests, Newman-Keuls tests, or Tukey's honestly significant difference tests (as appropriate depending on the number of comparisons) comparing all conditions to each other.

All statistical analyses were performed with Statistica version 9 (StatSoft). Differences were considered significant for $p<0.05$. All data are expressed as mean \pm SEM.

\section{Results}

Effects of acute estrogen treatment in chronically estrogendeprived males (group 1)

To assess behavioral effects of a rapid increase in estrogen bioavailability, CX males were chronically treated with SILASTIC T implants and received twice daily injections of the aromatase inhibitor VOR. They were thus exposed to the full range of androgenic effects of $\mathrm{T}$, whereas genomic effects of estrogens were dramatically reduced. As predicted (Balthazart et al., 2009b), this treatment nearly eliminated copulation (Fig. 2).

The acute intracerebroventricular injection of $17 \beta-\mathrm{E}_{2}(50 \mu \mathrm{g})$ to these animals resulted within $15 \mathrm{~min}$ in a doubling of RCSM frequency (Fig. $3 A ; F_{(1,10)}=13.854, p=0.004$; experiment 1 ), yet
RCSM frequencies did not reach the same level as in control birds that were not chronically treated with VOR. A higher dose of $\mathrm{E}_{2}(100 \mu \mathrm{g})$ increased RCSM frequency to the same extent $\left(F_{(1,10)}=\right.$ 16.264, $p=0.002$; vehicle, $26.5 \pm 8.7 ; \mathrm{E}_{2}$, $53.7 \pm 9.7$; experiment 2 ). In contrast, $\mathrm{E}_{2}$ (50 or $100 \mu \mathrm{g}$ ) had little or no effect on CCM frequency $\left(50 \mu\right.$ g: Fig. $3 B, F_{(1,10)}=$ $2.500, p=0.144$, experiment $1 ; 100 \mu \mathrm{g}$ : no behavior was displayed by any subject regardless of the treatment; experiment 2). To determine whether this effect of $E_{2}$ was mediated by its action at the membrane or inside the cells, we tested the effect of $\mathrm{E}_{2}-$ BSA, which does not cross the cell membrane. This membrane-impermeable analog mirrored the effect of the free estrogen on RCSM frequencies (Fig. 3C; $F_{(1,9)}=12.41, p=0.006$; experiment 3 ), indicating that this effect is initiated at the cell membrane. In contrast, no copulatory behavior was displayed by any subject regardless of the treatment, suggesting the lack of a membrane-initiated effect on copulatory behavior.

No effect of the order of treatments $(F \leq 0.659, p \geq 0.437)$ or interaction between the treatments and their order $(F \leq 2.979$, $p \geq 0.118$ ) was detected with the exception of an interaction that was detected for $\mathrm{E}_{2}$ at $50 \mu \mathrm{g}$ (Fig. $3 A ; F_{(1,10)}=5.98, p=0.034$ ). However, this interaction is associated with a more pronounced effect of $E_{2}$ in the subgroup that received $E_{2}$ in the first test compared with the second test, suggesting that it cannot be attributed to a long-term treatment effect. Overall, this absence of treatment effects and interaction between treatments and orders suggests that there is no carryover effect indicative of long-term effects of estrogens.

Together, these data clearly indicate that a single injection of $\mathrm{E}_{2}$ or $\mathrm{E}_{2}-\mathrm{BSA}$ can acutely restore the appetitive component of male sexual behavior in estrogen-deprived males. This suggests that the neural circuits underlying this aspect of the behavior are significantly modulated by nongenomic actions of estrogens. The fact that $\mathrm{E}_{2}$ did not restore RCSM frequencies to the level displayed by control animals suggests that some genomic priming by estrogens might additionally be necessary or alternatively that the acute treatment provided here was suboptimal. In contrast, these data provide no information on whether estrogens acutely influence copulatory behavior. Males chronically depleted of estrogens showed no or very little copulatory behavior. Neural circuits controlling this behavioral component may require a partial genomic priming by estrogens before these steroids can exert any acute action. This idea was tested in a second group of experiments by acutely blocking estrogen action or synthesis in males exposed to the androgenic and estrogenic metabolites of T.

\section{Effects of blockade of local estrogen action or synthesis on sexually active males (group 2)}

We next tested whether behavioral effects of endogenous estrogens produced by $\mathrm{T}$ aromatization in the brain would be rapidly blocked by the estrogen receptor antagonists ICI and TMX. In $\mathrm{CX}+\mathrm{T}$ males displaying the full spectrum of male-typical sexual behaviors, both antagonists significantly reduced RCSM frequencies within 15 min (Fig. $4 A ; F_{(2,24)}=23.69$, $p<0.001$; experiment 4$)$. This inhibition was even more pronounced when 

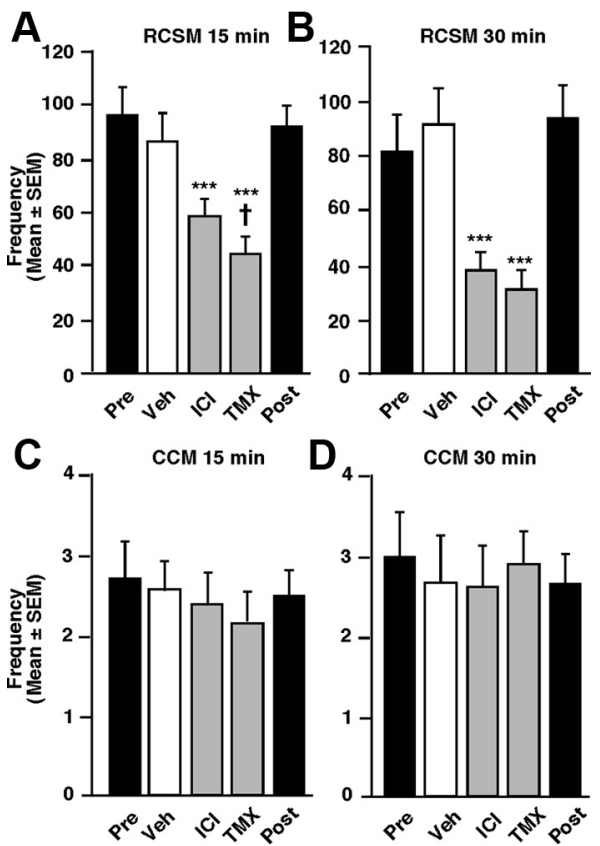

Figure 4. Effects of acute blockade of estrogen receptors on the ASB and CSB of fully active males (group 2). The blockade of estrogen action by the estrogen receptor antagonists ICI (50 $\mu \mathrm{g})$ and TMX $(50 \mu \mathrm{g})$ acutely inhibits RCSM frequency $(\boldsymbol{A}, \boldsymbol{B}, n=15)$ but not CCM frequency $(\boldsymbol{C}$, $\boldsymbol{D}, n=13$ and 15 , respectively) within 15 or 30 min compared with vehicle (Veh) injection (white bars). The "Pre" and "Post" black bars provide reference behavior frequencies after vehicle intracerebroventricular injections performed before and after the acute treatments, but these data are not included in the statistical analyses. ${ }^{* * *} p<0.001$ versus vehicle; ${ }^{\dagger} p<0.05$ versus ICl by Newman-Keuls post hoc tests after identification of a significant treatment effect (repeated-measure) by two-way ANOVA.

tests were performed $30 \mathrm{~min}$ after the intracerebroventricular injection (Fig. $4 B ; F_{(2,24)}=24.705, p<0.001$; experiment 5). In contrast, regardless of timing, these antagonists did not affect copulatory behavior (Fig. $4 C, D ; 15 \mathrm{~min}: F_{(2,20)}=1.122, p=0.345$, experiment 6; 30 min: $F_{(2,24)}=0.101, p=0.903$, experiment 7). The acute blockade of estrogen action thus significantly affected a measure of ASB but not its consummatory aspect, just as did the acute stimulation by $\mathrm{E}_{2}$ in the first group of experiments.

No order effect of the treatment was detected $(F \leq 1.769, p \geq$ $0.212)$ except for RCSM tested after $30 \min \left(F_{(2,12)}=11.02, p=\right.$ 0.010 ; baseline behavior was slightly different between subgroups). However, no interaction was detected in any of these experiments $(F \leq 1.695, p \geq 0.183)$. In addition, all comparisons of the pretests and posttests was not significant $(t \leq 1.389, p \geq$ 0.190 ). Thus, these behavioral responses do not seem to be affected by long-term effects of estrogens.

Nongenomic effects of estrogens are potentially mediated by different membrane receptors, including nuclear estrogen receptors of the $\alpha$ or $\beta$ subtype associated with the neuronal membrane (Micevych and Dominguez, 2009) but also G-protein-coupled receptors, such as GPR30 (Revankar et al., 2005; Prossnitz et al., 2008) and $\mathrm{G}_{\mathrm{q}}$-mER (Roepke et al., 2009). ICI and TMX block some, but definitely not all, of these receptors. ASB and CSB could thus be acutely regulated by estrogens through different receptors, thus explaining why these two aspects of behavior were differentially affected by these antagonists. To test this possibility, birds were tested again but this time $30 \mathrm{~min}$ after an acute blockade of estrogen synthesis. A single injection of both the steroidal (ATD) and nonsteroidal (VOR) aromatase inhibitors significantly decreased ASB (Fig. $5 A ; F_{(2,18)}=15.31, p<0.001$; exper-
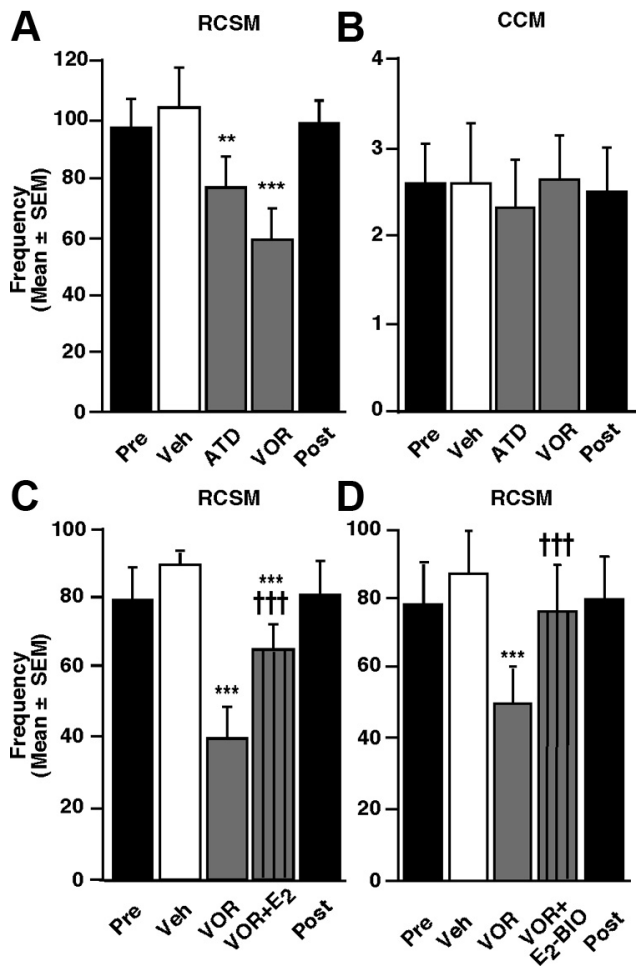

Figure 5. Effects of acute deprivation in brain-derived estrogens on the ASB and CSB of fully active males (group 2). Blockade of local estrogen synthesis by the aromatase inhibitors ATD (50 $\mu \mathrm{g})$ or VOR $(50 \mu \mathrm{g})$ inhibits RCSM frequency $(\boldsymbol{A}, \boldsymbol{C}, \boldsymbol{D})$ but not CCM frequency $(\boldsymbol{B})$ within $30 \mathrm{~min}$. $E_{2}(50 \mu \mathrm{g} ; C)$ or its membrane-impermeant analog $E_{2}-$ biotin $\left(E_{2}-B I 0,50 \mu g E_{2}\right.$ equivalent; $\left.\boldsymbol{D}\right)$ injected 15 min after VOR counteracts its effect on RCSM. The "Pre" and "Post" black bars provide reference behavior frequencies after vehicle intracerebroventricular injections performed before and after the acute treatments, but these data are not included in the statistical analyses. ${ }^{* *} p<0.01$ and ${ }^{* * *} p<0.001$ versus vehicle (Veh) ${ }^{{ }^{t+t}} p<0.001$ vs VOR by Newman-Keuls post hoc tests after identification of a significant treatment effect (repeated measure, $n=12$ in each case) by two-way ANOVA.

iment 8), thus demonstrating that the suppression of estrogen production has the same effect as the blockade of its action and, notably, that the relevant estrogens are produced locally in the brain. However, CSB was still unchanged by aromatase inhibitors (Fig. $5 B ; F_{(2,18)}=0.161, p=0.851$; experiment 9).

No order effect $(F \leq 0.438, p \geq 0.657)$ nor interaction was detected in any of these experiments $(F \leq 1.146, p \geq 0.366)$. In addition, none of the comparisons of the pretests and posttests was significant ( $t \leq 0.168, p \geq 0.869$ ). These results again indicate that these effects are not associated with long-term actions of estrogens.

Importantly, the VOR-induced inhibition of ASB was almost completely prevented by an $\mathrm{E}_{2}$ intracerebroventricular injection (50 or $100 \mu \mathrm{g}$ ) administered $15 \mathrm{~min}$ after VOR (Fig. $5 C$; $50 \mu \mathrm{g}$ : $F_{(2,18)}=50.152, p<0.001$; experiment 10$)$. Thus, the behavioral inhibition does not result from nonspecific adverse effects of the aromatase inhibitor but specifically from the depletion of endogenous estrogens. This rescue of VOR treatment effects by $E_{2}$ was mimicked by another membrane-impermeable estrogen analog $\mathrm{E}_{2}$-biotin $\left(50 \mu \mathrm{g}\right.$; Fig. $5 D ; F_{(2,18)}=31.01, p<0.001$; experiment 11 ), further confirming that rapid effects of $E_{2}$ are initiated at the membrane. Again, no order effect $(F \leq 0.231, p \geq 0.797)$ was detected in these experiments. No interaction was found after $E_{2}$ injection $\left(F_{(4,18)}=2.686, p=0.064\right)$, but a significant interaction was detected with $\mathrm{E}_{2}$-biotin $\left(F_{(4,18)}=4.093, p=0.015\right)$. This interaction results from a decreased stimulation by $\mathrm{E}_{2}$-biotin in 


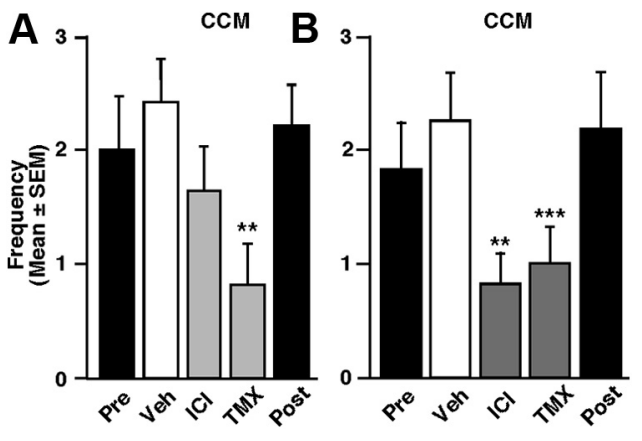

Figure 6. Effects of acute blockade of estrogen action or synthesis on copulatory behavior of behaviorally active males tested in large test chambers (group 2). The acute blockade of estrogen action by general estrogen antagonists $(\boldsymbol{A}, n=14)$ or synthesis by aromatase inhibitors $(\boldsymbol{B}, n=12)$ profoundly inhibits CSB when measured in a large test arena $(90 \times 90 \times 50 \mathrm{~cm}) 30 \mathrm{~min}$ after injection compared with control vehicle (Veh) injection. The "Pre" and "Post" black bars provide reference behavior frequencies after vehicle intracerebroventricular injections performed before and after the acute treatments, but these data are not included in the statistical analyses. ${ }^{* *} p<0.01$ and ${ }^{* * *} p<$ 0.001 versus vehicle (Veh) by Newman-Keuls post hoc tests after identification of a significant treatment effect (repeated measure) by two-way ANOVA.

the subgroup that received this treatment last (order in this subgroup PG/VOR/VOR $+\mathrm{E}_{2}$ - biotin). This decreased reaction cannot be ascribed to lasting effects of the previous injection of VOR because a marked stimulation by $\mathrm{E}_{2}$ - biotin was observed in the subgroup exposed in sequence to $\mathrm{VOR} / \mathrm{VOR}+\mathrm{E}_{2}$ - biotin/PG. In addition, none of the comparisons of the pretests and posttests were found to be statistically significant ( $t \leq 0.219, p \geq 0.830$ ). Overall, these findings support the independence of these effects from long-term actions of estrogens.

One explanation for the striking discrepancy between rapid effects of estrogens on ASB and CSB could reside in the fact that copulatory behavior was tested in a small arena in which motivational decreases might not affect performance because both partners are in such close proximity that males reflexively perform the copulatory sequence in the absence of sexual motivation; the simple contact with the mate would trigger the performance of the motor copulatory sequence. To test this hypothesis, effects of estrogen receptor antagonists and aromatase inhibitors on CSB were tested again but this time in a larger arena in which females could more easily escape so that males had to actively pursue them to copulate successfully. In this new context, TMX, but not ICI, significantly inhibited copulation (Fig. $6 A ; F_{(2,22)}=8.591$, $p<0.001$; experiment 12). Furthermore, both aromatase inhibitors profoundly inhibited CSB (Fig. $6 B ; F_{(2,18)}=10.943, p<$ 0.001 ; experiment 13 ). Thus, the acute blockade of estrogen action affects CSB in contexts in which males must be sexually motivated and actively chase the female to mate.

Again, the analyses did not reveal any order effect ( $F \leq 2.367$, $p \geq 0.149)$ nor interaction between treatments and their order ( $F \leq 1.317, p \geq 0.294$ ). In addition, none of the comparisons between the pretests and posttests was significant $(t \leq 1.000, p \geq$ 0.338 ). Overall, this absence of order effects and of interaction between treatments and orders suggests that there is no carryover indicative of long-term effects of estrogens.

Effect of changes in brain-derived estrogens on the learned social proximity response in sexually active males (group 3) The results described so far suggested that the nongenomic actions of estrogens might preferentially control the sexual motiva- tion but not sexual performance. To assess this possibility further, another group of CX + T males was used to test the acute effects of brain-derived estrogens on another measure of ASB, the learned social proximity response. These animals were also used to demonstrate the reproducibility of some of the results presented previously.

As shown previously (Balthazart et al., 1998), the animals progressively learned to stand in front of the window (from $\sim 60 \mathrm{~s}$ during the first test to $250 \mathrm{~s}$ of $300 \mathrm{~s}$ at the plateau) and spent an increasing amount of time looking at the female (from $\sim 45 \mathrm{~s}$ during the first test to $200 \mathrm{~s}$ at the plateau). Thus, there was a significant change in these behaviors across the eight acquisition tests (repetition effect: Square, $F_{(7,91)}=12.530, p<0.0001$; Look, $\left.F_{(7,91)}=13.936, p<0.0001\right)$. This response was then stable over time even when tested in extinction as revealed by the comparison of the time spent in the square and looking between the last acquisition test and the first two extinction tests (repetition effect: Square, $F_{(2,26)}=2.213, p=0.129$; Look, $F_{(2,26)}=$ 2.328, $p=0.117$ ).

The learned social proximity response, as assessed by the time spent near the window (square) and looking at the female, was acutely reduced by aromatase inhibition, and this effect was completely prevented by $\mathrm{E}_{2}$ (Fig. $7 A, B$; Square, $F_{(2,26)}=4.867, p=$ 0.016; Look, $F_{(2,26)}=9.284, p<0.001$; experiment 14). No effect of the order of the treatments (Square, $F_{(2,13)}=0.009, p=0.991$; Look, $\left.F_{(2,13)}=0.114, p=0.893\right)$ or their interaction with these treatments (Square, $F_{(4,26)}=0.094, p=0.983$; Look, $F_{(4,26)}=$ $0.284, p=0.885$ ) was noticed. In addition, the pretests and posttests did not differ either $(t \leq 0.509, p \geq 0.618)$.

The effects of these treatments (VOR and VOR $+\mathrm{E}_{2}$ compared with PG) were then tested on the RCSM frequency, and copulatory behavior was assessed in the small and large test chambers. These experiments fully confirmed the effects observed in the second set of animals in the current study: changes in brain-derived estrogens induced parallel changes in RCSM frequency (Fig. $7 C ; F_{(2,12)}=13.965, p<0.001$; experiment 15 ), as well as in sexual performance when measured in a large arena in which the female can easily escape the male (Fig. $7 D ; F_{(2,12)}=$ $7.429, p=0.008$; experiment 17 ) but not in the small arena in which both partners are in very close proximity (Fig. $7 E ; F_{(2,12)}=$ $0.888, p=0.437$; experiment 16$)$. Again, no order effect $(F \leq$ $0.864, p \geq 0.468)$ nor interaction $(F \leq 2.279, p \geq 0.120)$ was detected in any of these experiments, and no difference was found between the behavioral frequencies displayed during the pretests and posttests ( $t \leq 0.577, p \geq 0.579$ ), with the exception of the RCSM test $(t=6.271, p<0.0002$; overall minor decrease in all subgroups over the course of the experiment).

Together, these results further demonstrate that acute changes in local estrogen bioavailability do not alter the ability of male quail to produce a highly coordinated sexual motor response. Indeed, the lack of effect in the small arena demonstrates that the absence of estrogens does not impair the ability of the male to mount and perform the highly stereotypical CCM. However, copulatory behavior can only be observed after the male has searched for and approached a female. When examined in the large arena, an absence of sexual performance thus indirectly reflects a lack of motivation. That sexual performance is only affected by estrogens in the large arena clearly suggests that brainderived estrogens rapidly affect sexual motivation but not performance as supported by the results obtained from two independent measures of ASB. 


\section{Discussion}

The present experiments show that $17 \beta-\mathrm{E}_{2}$ significantly activates and estrogen receptor antagonists inhibit, with latencies in the order of minutes, the expression of behaviors reflecting sexual motivation in male quail. Mechanistically, these effects appear to be initiated at the cell membrane level because these effects are mimicked by the injection of membraneimpermeable estrogens, such as $\mathrm{E}_{2}-\mathrm{BSA}$ and $\mathrm{E}_{2}$-biotin. Finally, the observation that ASB is blocked also within minutes by a single intracerebroventricular injection of aromatase inhibitors indicates that endogenous estrogens locally produced in the brain are actually exerting these rapid controls of sexual motivation.

The activation of appetitive and consummatory male sexual behavior by the genomic action of brain-derived estrogens has been extensively documented across vertebrates (Christensen and Clemens, 1974, 1975; Balthazart et al., 1995; Vagell and McGinnis, 1997; Bakker et al., 2004; Taziaux et al., 2004). In quail specifically, the activation of copulatory behavior and appetitive responses, such as the female-induced increase in RCSM frequency and the learned social proximity response, requires local $\mathrm{T}$ aromatization in the preoptic area (Balthazart et al., 1990b, 1997; Riters et al., 1998). Recently, it had been suggested that estrogens also acutely control both behavioral components with a more pronounced effect on the appetitive aspect of maletypical sexual behavior in birds at least (Cross and Roselli, 1999; Cornil et al., 2006a,b; Taziaux et al., 2007). However, some of these effects were highly variable. This might in part be explained by the fact that all compounds were administered peripherally but also by the relative lack of previous genomic priming by the androgenic and/or estrogenic metabolites of T. Previous studies have indeed tested whether acute administration of $\mathrm{E}_{2}$ could restore sexual behavior in CX rats (Cross and Roselli, 1999) or in CX quail treated with a suboptimal dose of $\mathrm{T}$ whose effects were quite difficult to titrate (Cornil et al., 2006a). The present design circumvented these problems by administering all acute treatments directly in the brain (third ventricle) and testing the effects of $E_{2}$ either (1) in males chronically supplied with physiological $\mathrm{T}$ concentrations but chronically depleted in estrogens (group 1 of birds) or (2) in males chronically treated with $\mathrm{T}$ but acutely deprived of estrogens (groups 2 and 3 ). The present data demonstrate that brain-derived estrogens can acutely facilitate a measure of ASB in the absence of genomic activation by estrogens (experiments 1 and 3), although restoration seems to be more complete when genomic priming by both androgenic and estrogenic metabolites is present and local aromatization is only inhibited acutely (experiments 10 , 11 , and 15). In contrast, the absence of effect of $E_{2}$ on the fully inhibited copulatory behavior of males chronically deprived of estrogens (experiment 2) indicates that the neural circuits underlying the control of the copulatory sequence critically depend on the genomic activation by estrogens.
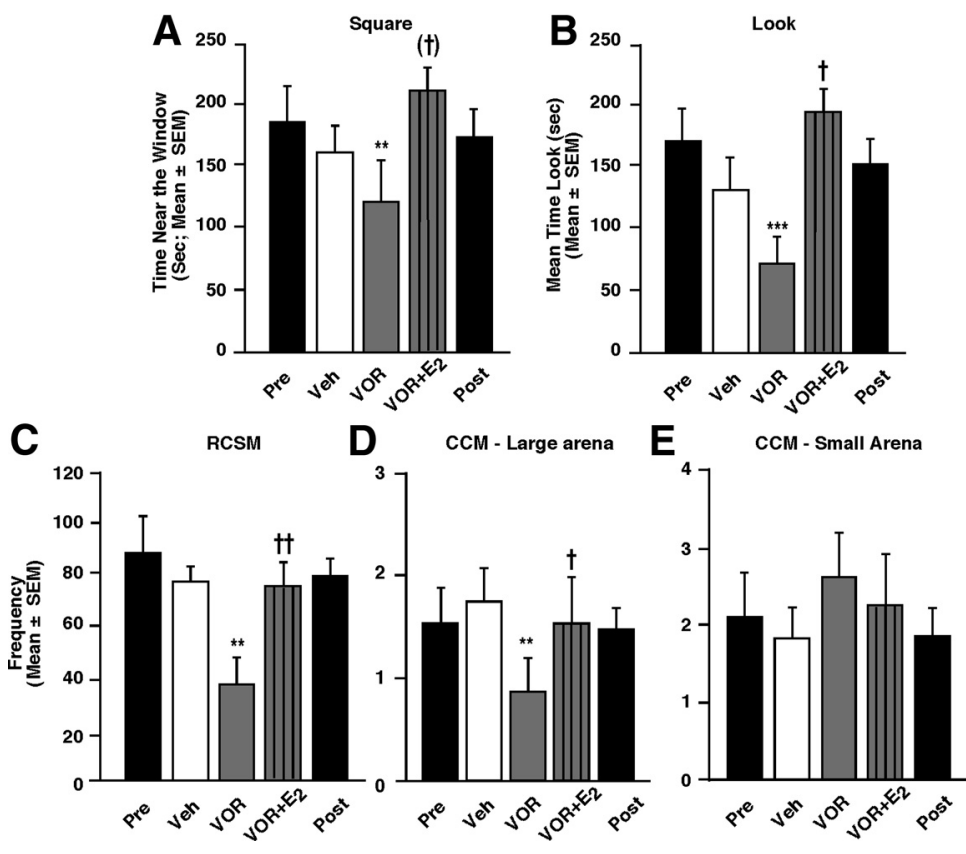

Figure 7. Effects of acute blockade of brain estrogen synthesis associated or not with an acute $E_{2}$ injection on appetitive and consummatory aspects of male sexual behavior in sexually active males (group 3). Blockade of local estrogen synthesis by the aromatase inhibitor VOR $(50 \mu \mathrm{g})$ acutely reduces whereas $\mathrm{E}_{2}(50 \mu \mathrm{g})$ restores the time spent near the window $(\boldsymbol{A})$ and looking at ehavior frequencies after vehicle intracerebroventricular injections performed before and after the acute treatments. ${ }^{* *} p<0.01$ and ${ }^{* * *} p<0.001$ versus vehicle (Veh); ${ }^{(+)} p<0.10,{ }^{\dagger} p<0.05,{ }^{\dagger+} p<0.01$ versus VOR by Newman-Keuls post hoc tests after identification of a significant treatment effect (repeated measure) by two-way ANOVA.

Together, these data demonstrate that centrally administered $17 \beta-\mathrm{E}_{2}$ rapidly stimulates sexual motivation but not performance (unless performance depends on motivation, as in the tests performed in the large arena). Importantly, the basal (control) behavioral activity was remarkably stable across tests despite repeated treatments with various drugs. No effect of the order in which treatments were administered to different subgroups of birds could be generally detected, and there were usually no differences in behavioral frequencies between pretests and posttests, indicating that there is no long-term (presumably genomic) effect coupled to these acute treatments. Moreover, these membrane-initiated effects are faster than the typical hours/days required for genomic actions. These data imply that the effects are independent of new transcription and rely on nongenomic mechanisms.

It was proposed recently that $17 \beta-\mathrm{E}_{2}$ satisfies most, if not all, criteria needed to classify the steroid in the brain as a neuromodulator rather than a hormone (Balthazart and Ball, 2006; Saldanha et al., 2011). Among these criteria, the ability to exert rapid actions and the existence of rapid regulations of local synthesis were described in vitro, but clear evidence that $\mathrm{E}_{2}$ acts as a neuromodulator to alter behavioral responses was primarily lacking. The remarkable reduction of sexual motivation observed here after central blockade of either estrogen action or synthesis provides a clear example of rapid estrogenic effects on a complex behavioral response. More importantly, it provides direct evidence that the estrogens relevant for this rapid control are produced locally. Because membrane receptors underlying these effects are probably available continuously, local $\mathrm{E}_{2}$ concentration must vary rapidly to control these on/off switches in moti- 
vation. This conclusion provides a functional significance to the rapid fluctuations in aromatase activity described recently in brain areas controlling sexual behavior (Cornil et al., 2005b; Dickens et al., 2011; de Bournonville et al., 2012).

It has been demonstrated that preoptic aromatase activity is very rapidly inhibited in the male quail brain after sexual interactions with a female (de Bournonville et al., 2012). Somewhat surprisingly, however, this enzymatic decrease was already observed after only visual exposure to the female without the male having had an opportunity to copulate with her (Cornil et al., 2005b; de Bournonville et al., 2012). This decrease is therefore not the direct result of engaging in copulation per se. Based on this observation, it was hypothesized that the high aromatase activity and the resulting elevated local concentration of estrogens might be critical for promoting sexual motivation and appetitive behavior through which the male searches for and courts the female. Copulatory performance sensu stricto would then no longer depend on these rapid nongenomic effects of estrogens but rather on the action of other neurotransmitters, such as dopamine, that have been primed and/or enhanced by modifications of brain neurochemistry resulting from the transcriptional effects of estrogens (for a detailed discussion, see de Bournonville et al., 2012). This interpretation fits well with the present results demonstrating that $17 \beta-\mathrm{E}_{2}$ activates within minutes appetitive aspects of male sexual behavior in quail but that the activation of copulatory performance sensu stricto requires a more sustained stimulation by estrogens and is not affected by these steroids on a short-term timescale. Evidence coming from radioenzyme assays of aromatase activity after sexual interactions (Cornil et al., 2005b; de Bournonville et al., 2012) and from behavioral effects of intracerebroventricular pharmacological treatments (present study) thus converges to indicate that estrogens independently modulate appetitive and consummatory aspects of male sexual behavior by nongenomic and genomic mechanisms, respectively.

Developing and maintaining signaling mechanisms that operate in distinct temporal domains on an integrated set of behavioral responses may appear as a waste of resources. That these two modes of action regulate distinct behavioral components (motivation vs performance), however, makes good sense when considering the natural constraints associated with reproduction. In the temperate zone, reproduction is synchronized with environmental cues (e.g., day length, temperature, food availability, etc.) to limit reproductive efforts to seasonal time periods that are most favorable to mate and raise offspring. Seasonal changes in circulating hormones prepare the organisms for breeding (e.g., maturation of the reproductive tract, development of sexually dimorphic traits, etc). These physiological changes include a profound reorganization of the neuronal circuitry that controls the performance of coordinated motor sequences in response to sexual stimuli (Tramontin and Brenowitz, 2000). These processes involving extensive protein synthesis, neurogenesis, and axonal growth require time. The time course of estrogen transcriptional activity is well suited to address these needs within the time frame required for seasonal effects. However, on a shorter timescale, even when the reproductive system is fully mature, sexual activity is not observed constantly. Instead, animals display bouts of sexual activity alternating with other activities required to satisfy other needs (e.g., feeding, grooming, etc.). They also interrupt mating when it would be inappropriate or even dangerous (e.g., during a storm, in the presence of a predator or a competitor). Mechanisms have evolved to adapt organisms to these internal or external cues and acutely control the drive to engage in sexual behavior. Although it is often assumed that acute behavioral changes are mediated by classical neurotransmitters, we demonstrate here that the rapid on/off switches in sexual motivation are controlled, at least in part, by brain-derived estrogens. These results indicate that the same molecule has evolved mechanisms to control different aspects of behavior in distinct temporal domains. Given the pleiotropic effects of estrogens, one may wonder whether other responses associated with reproduction (e.g., territoriality, parenting) also depend on a slow genomic regulation of the neuronal plasticity underlying behavioral activation and an acute control of motivation to engage in behavior. Extending this duality to non-reproductive responses, such as changes in cognition or neuroprotection, might have profound clinical implications.

\section{References}

Adkins EK, Adler NT (1972) Hormonal control of behavior in the Japanese quail. J Comp Physiol Psychol 81:27-36. Medline

Bakker J, Honda S, Harada N, Balthazart J (2004) Restoration of male sexual behavior by adult exogenous estrogens in male aromatase knockout mice. Horm Behav 46:1-10. CrossRef Medline

Ball GF, Balthazart J (2010) Japanese quail as a model system for studying the neuroendocrine control of reproductive and social behaviors. ILAR J 51:310-325. Medline

Balthazart J, Ball GF (2006) Is brain estradiol a hormone or a neurotransmitter? Trends Neurosci 29:241-249. CrossRef Medline

Balthazart J, Foidart A, Hendrick JC (1990a) The induction by testosterone of aromatase activity in the preoptic area and activation of copulatory behavior. Physiol Behav 47:83-94. CrossRef Medline

Balthazart J, Evrard L, Surlemont C (1990b) Effects of the non-steroidal inhibitor R76713 on testosterone-induced sexual behavior in the Japanese quail (Coturnix coturnix japonica). Horm Behav 24:510-531. CrossRef Medline

Balthazart J, Reid J, Absil P, Foidart A, Ball GF (1995) Appetitive as well as consummatory aspects of male sexual behavior in quail are activated by androgens and estrogens. Behav Neurosci 109:485-501. CrossRef Medline

Balthazart J, Castagna C, Ball GF (1997) Aromatase inhibition blocks the activation and sexual differentiation of appetitive male sexual behavior in japanese quail. Behav Neurosci 111:381-397. CrossRef Medline

Balthazart J, Absil P, Gérard M, Appeltants D, Ball GF (1998) Appetitive and consummatory male sexual behavior in japanese quail are differentialy regulated by subregions of the preoptic medial nucleus. J Neurosci 18: 6512-6527. Medline

Balthazart J, Arnold AP, Adkins-Regan E (2009a) Sexual differentiation of brain and behavior in birds. In: Hormones, brain and behavior, Ed 2 (Pfaff DW, Arnold AP, Etgen AM, Fahrbach SE, Rubin RT, eds), pp 1745-1787. San Diego: Academic.

Balthazart J, Taziaux M, Holloway K, Ball GF, Cornil CA (2009b) Behavioral effects of brain-derived estrogens in birds. Ann N Y Acad Sci 1163: 31-48. CrossRef Medline

Charlier TD, Harada N, Balthazart J, Cornil CA (2011) Human and quail aromatase activity is rapidly and reversibly inhibited by phosphorylating conditions. Endocrinology 152:4199-4210. CrossRef Medline

Christensen LW, Clemens LG (1974) Intrahypothalamic implants of testosterone or estradiol and resumption of masculine sexual behavior in longterm castrated male rats. Endocrinology 95:984-990. CrossRef Medline

Christensen LW, Clemens LG (1975) Blockade of testosterone-induced mounting behavior in the male rat with intracranial application of the aromatization inhibitor, androst-1,4,6,-triene-3,17-dione. Endocrinology 97:1545-1551. CrossRef Medline

Cornil CA, Ball GF (2010) Effects of social experience on subsequent sexual performance in naive male Japanese quail (Coturnix japonica). Horm Behav 57:515-522. CrossRef Medline

Cornil CA, Holloway KS, Taziaux M, Balthazart J (2004) The effects of aromatase inhibition on testosterone-dependent conditioned rhythmic cloacal sphincter movement in male Japanese quail. Physiol Behav 83:99-105. CrossRef Medline

Cornil CA, Dejace C, Ball GF, Balthazart J (2005a) Dopamine modulates male sexual behavior in Japanese quail in part via actions on noradrenergic receptors. Behav Brain Res 163:42-57. CrossRef Medline 
Cornil CA, Dalla C, Papadopoulou-Daifoti Z, Baillien M, Dejace C, Balthazart J (2005b) Sexual behavior affects preoptic aromatase activity and brain monoamines' levels. Endocrinology 146:3809-3820. CrossRef

Cornil CA, Dalla C, Papadopoulou-Daifoti Z, Baillien M, Balthazart J (2006a) Estradiol rapidly activates male sexual behavior and affects brain monoamine levels in the quail brain. Behav Brain Res 66:110-123. CrossRef Medline

Cornil CA, Taziaux M, Baillien M, Ball GF, Balthazart J (2006b) Rapid effects of aromatase inhibition on male reproductive behaviors in Japanese quail. Horm Behav 49:45-67. CrossRef Medline

Cornil CA, Ball GF, Balthazart J, Charlier TD (2011) Organizing effects of sex steroids on brain aromatase activity in quail. PLoS One 6:e19196. CrossRef Medline

Cornil CA, Ball GF, Balthazart J (2012) Rapid control of male typical behaviors by brain-derived estrogens. Front Neuroendocrinol 33:425-446. CrossRef Medline

Cross E, Roselli CE (1999) 17 $\beta$-estradiol rapidly facilitates chemoinvestigation and mounting in castrated male rats. Am J Physiol 276: R1346-R1350. Medline

de Bournonville C, Dickens MJ, Ball GF, Balthazart J, Cornil CA (2012) Dynamic changes in brain aromatase activity following sexual interactions: where, when and why? Psychoneuroendocrinology. Advance online publication. doi:10.1016/j.psyneuen.2012.09.001. CrossRef Medline

Delville Y, Hendrick JC, Sulon J, Balthazart J (1984) Testosterone metabolism and testosterone-dependent characteristics in Japanese quail. Physiol Behav 33:817-823. CrossRef Medline

Dewing P, Boulware MI, Sinchak K, Christensen A, Mermelstein PG, Micevych P (2007) Membrane estrogen receptor-alpha interactions with metabotropic glutamate receptor la modulate female sexual receptivity in rats. J Neurosci 27:9294-9300. CrossRef Medline

Dickens MJ, Cornil CA, Balthazart J (2011) Acute stress differentially affects aromatase activity in specific brain nuclei of adult male and female quail. Endocrinology 152:4242-4251. CrossRef Medline

Domjan M, Hall S (1986) Determinants of social proximity in Japanese quail (Coturnix coturnix japonica): male behavior. J Comp Psychol 100: 59-67. CrossRef

Domjan M, Akins C, Vandergriff DH (1992) Increased responding to female stimuli as a result of sexual experience: tests of mechanisms of learning. Q J Exp Psychol 45B:139-157. Medline

Etgen AM, Pfaff DW (2009) Molecular mechanisms of hormone action on behavior. San Diego: Academic.

Germain PS, Metezeau P, Tiefenauer LX, Kiefer H, Ratinaud MH, Habrioux G (1993) Use of a biotinyl-estradiol derivative to demonstrate estradiolmembrane binding sites on adherent human breast cancer MCF-7 cells. Anticancer Res 13:2347-2353. Medline

Holloway KS, Balthazart J, Cornil CA (2005) Androgen mediation of conditioned rhythmic cloacal sphincter movements in Japanese quail (Coturnix japonica). J Comp Psychol 119:49-57. CrossRef Medline

Hutchison JB, Steimer TJ, Hutchison RE (1986) Formation of behaviorally active estrogen in the dove brain: induction of preoptic aromatase by intracranial testosterone. Neuroendocrinology 43:416-427. CrossRef Medline

Hutchison RE (1978) Hormonal differentiation of sexual behavior in Japanese quail. Horm Behav 11:363-387. CrossRef Medline

Kleitz-Nelson HK, Cornil CA, Balthazart J, Ball GF (2010) Differential effects of central injections of D1 and D2 receptor agonists and antagonists on male sexual behavior in Japanese quail. Eur J Neurosci 32:118-129. CrossRef Medline

Kow LM, Pfaff DW (2004) The membrane actions of estrogens can potentiate their lordosis behavior-facilitating genomic actions. Proc Natl Acad Sci U S A 101:12354-12357. CrossRef Medline

Micevych P, Dominguez R (2009) Membrane estradiol signaling in the brain. Front Neuroendocrinol 30:315-327. CrossRef Medline

Naftolin F, Ryan KJ, Davies IJ, Reddy VV, Flores F, Petro Z, Kuhn M, White RJ, Takaoka Y, Wolin L (1975) The formation of estrogens by central neuroendocrine tissues. Rec Prog Horm Res 31:295-319. Medline

Prossnitz ER, Sklar LA, Oprea TI, Arterburn JB (2008) GPR30: a novel therapeutic target in estrogen-related disease. Trends Pharmacol Sci 29:116123. CrossRef Medline
Qiu J, Bosch MA, Tobias SC, Grandy DK, Scanlan TS, Ronnekleiv OK, Kelly MJ (2003) Rapid signaling of estrogen in hypothalamic neurons involves a novel G-protein-coupled estrogen receptor that activates protein kinase C. J Neurosci 23:9529-9540. Medline

Remage-Healey L, Joshi NR (2012) Changing neuroestrogens within the auditory forebrain rapidly transform stimulus selectivity in a downstream sensorimotor nucleus. J Neurosci 32:8231-8241. CrossRef Medline

Remage-Healey L, Coleman MJ, Oyama RK, Schlinger BA (2010) Brain estrogens rapidly strengthen auditory encoding and guide song preference in a songbird. Proc Natl Acad Sci U S A 107:3852-3857. CrossRef Medline

Remage-Healey L, Maidment NT, Schlinger BA (2008) Forebrain steroid levels fluctuate rapidly during social interactions. Nat Neurosci 11:13271334. CrossRef Medline

Revankar CM, Cimino DF, Sklar LA, Arterburn JB, Prossnitz ER (2005) A transmembrane intracellular estrogen receptor mediates rapid cell signaling. Science 307:1625-1630. CrossRef

Riters LV, Absil P, Balthazart J (1998) Effects of brain testosterone implants on appetitive and consummatory components of male sexual behavior in Japanese quail. Brain Res Bull 47:69-79. CrossRef Medline

Robinson JE, Follett BK (1982) Photoperiodism in Japanese quail: the termination of seasonal breeding by photorefractoriness. Proc R Soc Lond B Biol Sci 215:95-116. CrossRef Medline

Roepke TA, Qiu J, Bosch MA, Rønnekleiv OK, Kelly MJ (2009) Cross-talk between membrane-initiated and nuclear-initiated oestrogen signalling in the hypothalamus. J Neuroendocrinol 21:263-270. CrossRef Medline

Roselli CE, Horton LE, Resko JA (1985) Distribution and regulation of aromatase activity in the rat hypothalamus and limbic system. Endocrinology 117:2471-2477. CrossRef Medline

Sachs BD (1967) Photoperiodic control of the cloacal gland of the Japanese quail. Science 157:201-203. CrossRef Medline

Saldanha CJ, Remage-Healey L, Schlinger BA (2011) Synaptocrine signaling: steroid synthesis and action at the synapse. Endocr Rev 32:532-549. CrossRef Medline

Santen RJ, Brodie H, Simpson ER, Siiteri PK, Brodie A (2009) History of aromatase: saga of an important biological mediator and therapeutic target. Endocr Rev 30:343-375. CrossRef Medline

Seiwert CM, Adkins-Regan E (1998) The foam production system of the male Japanese quail: characterization of structure and function. Brain Behav Evol 52:61-80. CrossRef Medline

Stevis PE, Deecher DC, Suhadolnik L, Mallis LM, Frail DE (1999) Differential effects of estradiol and estradiol-BSA conjugates. Endocrinology 140: 5455-5458. CrossRef Medline

Taziaux M, Cornil CA, Balthazart J (2004) Aromatase inhibition blocks the expression of sexually-motivated cloacal gland movements in male quail. Behav Processes 67:461-469. CrossRef Medline

Taziaux M, Keller M, Bakker J, Balthazart J (2007) Sexual behavior activity tracks rapid changes in brain estrogen concentrations. J Neurosci 27: 6563-6572. CrossRef Medline

Thompson RR, Goodson JL, Ruscio MG, Adkins-Regan E (1998) Role of the archistriatum nucleus taeniae in the sexual behavior of male Japanese quail (Coturnix japonica): a comparison of function with the medial nucleus of the amygdala in mammals. Brain Behav Evol 51:215-229. CrossRef Medline

Tramontin AD, Brenowitz EA (2000) Seasonal plasticity in the adult brain. Trends Neurosci 23:251-258. CrossRef Medline

Tremere LA, Pinaud R (2011) Brain-generated estradiol drives long-term optimization of auditory coding to enhance the discrimination of communication signals. J Neurosci 31:3271-3289. CrossRef Medline

Tremere LA, Jeong JK, Pinaud R (2009) Estradiol shapes auditory processing in the adult brain by regulating inhibitory transmission and plasticityassociated gene expression. J Neurosci 29:5949-5963. CrossRef Medline

Tsai MJ, O’Malley BW (1994) Molecular mechanisms of action of steroid/ thyroid receptor superfamily members. Annu Rev Biochem 63:451-486. CrossRef Medline

Vagell ME, McGinnis MY (1997) The role of aromatization in the restoration of male rat reproductive behavior. J Neuroendocrinol 9:415-421. Medline

Woolley CS (2007) Acute effects of estrogen on neuronal physiology. Annu Rev Pharmacol Toxicol 47:657-680. CrossRef Medline 